\section{Allogeneic stem cell transplantation in second complete remission for core binding factor acute myeloid leukemia: a study from the Acute Leukemia Working Party of the European Society for Blood and Marrow Transplantation}

Kazimierz Halaburda ${ }^{1 *}$ Myriam Labopin $, 2,3^{*}$ Audrey Mailhol ${ }^{2}$ Gerard Socié 4 Charles Craddock, ${ }^{5}$ Mahmoud Aljurf, ${ }^{6}$ Dietrich Beelen, ${ }^{7}$ Jan J. Cornelissen, ${ }^{8}$ Jean-Henri Bourhis, ${ }^{9}$ Hélène Labussière-Wallet, ${ }^{10}$ Didier Blaise,${ }^{11}$ Tobias GeddeDahl, ${ }^{12}$ Maria Gilleece, ${ }^{13}$ Ibrahim Yakoub-Agha, ${ }^{14}$ Ghulam Mufti, ${ }^{15}$ Jordi Esteve, ${ }^{16}$ Mohamad Mohty ${ }^{2,3}$ and Arnon Nagler ${ }^{2,17^{\star}}$

${ }^{1}$ Institute of Haematology and Transfusion Medicine, Warsaw, Poland; ${ }^{2}$ EBMT Paris Study Office, Paris, France; ${ }^{3}$ Saint Antoine Hospital, Paris, France; ${ }^{4}$ St. Louis Hospital, Paris, France; ${ }^{5}$ Queen Elizabeth Hospital, Birmingham, UK; ${ }^{6}$ King Faisal Hospital, Riyadh, Saudi Arabia; ${ }^{7}$ University Hospital, Essen, Germany; ${ }^{8}$ Erasmus MC Cancer Institute, Rotterdam, the Netherlands; ' 9 Gstave Roussy Institut de Cancérologie, Villejuif, France; ${ }^{10}$ Hospices Civils de Lyon, Centre Hospitalier Lyon Sud, Lyon, France; ${ }^{11}$ Institut Paoli Calmettes, Marseille, France; ${ }^{12}$ Oslo University Hospital, Oslo, Norway; ${ }^{13}$ St James's Institute of Oncology, Leeds, UK; ${ }^{14} \mathrm{CHU}$ de Lille, LIRIC, INSERM U995, Université de Lille, 59000 Lille, France; ${ }^{15}$ GKT School of Medicine, London, UK; ${ }^{16} \mathrm{Hospital}$ Clinic, Barcelona, Spain and ${ }^{17}$ Chaim Sheba Medical Center, Tel Hashomer, Israel

${ }^{*} \mathrm{KH}, \mathrm{ML}$ and $\mathrm{AN}$ contributed equally as co-first authors.

\section{ABSTRACT}

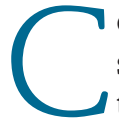
ore binding factor acute myeloid leukemia (AML) comprises two subtypes with distinct cytogenetic abnormalities of either $\mathrm{t}(8 ; 21)(\mathrm{q} 22 ; \mathrm{q} 22)$ or $\operatorname{inv}(16)(\mathrm{p} 13 \mathrm{q} 22) / \mathrm{t}(16 ; 16)(\mathrm{p} 13 ; \mathrm{q} 22)$. Since longterm response to chemotherapy in these leukemias is relatively good, allogeneic hematopoietic stem cell transplantation is considered in patients who relapse and achieve second complete remission. To evaluate the outcomes of allogeneic transplantation in this indication, we studied 631 patients reported to the European Society for Blood and Marrow Transplantation Registry between the years 2000 and 2014. Leukemia-free survival probabilities at two and five years were $59.1 \%$ and $54.1 \%$, while overall survival probabilities were $65 \%$ and $58.2 \%$, respectively. The incidence of relapse and risk of non-relapse mortality at the same time points were $19.8 \%$ and $22.5 \%$ for relapse and $20.9 \%$ and $23.3 \%$ for non-relapse mortality, respectively. The most important adverse factors influencing leukemia-free and overall survival were: leukemia with $\mathrm{t}(8 ; 21)$, presence of three or more additional chromosomal abnormalities, and Karnofsky performance score $<80$. Relapse risk was increased in $t(8 ; 21)$ leukemia and associated with additional cytogenetic abnormalities as well as reduced intensity conditioning. Measurable residual disease in molecular evaluation before transplantation was associated with increased risk of relapse and inferior leukemia-free survival.

\section{Introduction}

Core binding factor (CBF) leukemia represents up to $12 \%$ of all newly diagnosed adult acute myeloid leukemia (AML). ${ }^{1}$ Chromosomal markers of CBF AML include $\mathrm{t}(8 ; 21)(\mathrm{q} 22 ; \mathrm{q} 22)$ and inv(16)(p13q22) or less frequently $\mathrm{t}(16 ; 16)(\mathrm{p} 13 ; \mathrm{q} 22)$, further described jointly as inv(16). As a result of chromosomal abnormalities, fusion transcripts RUNX1-RUNX1T1 in $\mathrm{t}(8 ; 21)$ and CBFB-MYH11 in inv(16) emerge. The tran-
Haematologica 2020

Volume 105(6):1723-1730

\section{Correspondence:}

KAZIMIERZ HALABURDA

khalab30@wp.pl

Received: March 22, 2019.

Accepted: August 14, 2019.

Pre-published: August 22, 2019.

doi:10.3324/haematol.2019.222810

Check the online version for the most updated information on this article, online supplements, and information on authorship \& disclosures: www.haematologica.org/content/105/6/1723

(C)2020 Ferrata Storti Foundation

Material published in Haematologica is covered by copyright. All rights are reserved to the Ferrata Storti Foundation. Use of published material is allowed under the following terms and conditions:

https://creativecommons.org/licenses/by-nc/4.0/legalcode. Copies of published material are allowed for personal or internal use. Sharing published material for non-commercial purposes is subject to the following conditions:

https://creativecommons.org/licenses/by-nc/4.0/legalcode, sect. 3. Reproducing and sharing published material for commercial purposes is not allowed without permission in writing from the publisher. 
scripts represent molecular attributes of CBF AML and are driver mutations for leukemogenesis. They disrupt normal hematopoiesis dependent on core binding factor subunit $\alpha$ (RUNX1) and $\beta$ (CBFB) by silencing tumor suppressor genes leading to neoplastic transformation. ${ }^{2}$ Accompanying secondary gene mutations (mutations of NRAS, KIT, NF1, FLT3, KRAS, ASXL1\&2), additional cytogenetic abnormalities, and clinical features at diagnosis (age, white blood cell and blast counts, extramedullary involvement) affect treatment outcomes, but general prognosis in CBF AML remains favorable., ${ }^{3,4}$ Indeed, current induction chemotherapy standards lead to a complete remission (CR) rate of $87-89 \%$, involving a high proportion of younger patients. ${ }^{5,6}$ Repeated high or intermediatedose cytarabine consolidation provides long-term disease control in a large proportion of patients. Conventional chemotherapy results in long-term survival in $53-64 \%$ of patients. The major reason for treatment failure in $\mathrm{CBF}$ AML is relapse, reported in $30-50 \%$ of patients. ${ }^{7,8}$ Given the relatively favorable results of chemotherapy, patients with CBF leukemia are not usually candidates for allogeneic hematopoietic stem cell transplantation (HSCT) in first CR (CR1). However, CBF AML is a heterogeneous group of malignancies. Several variables, including type of CBF subunit involved, age, additional molecular or cytogenetic abnormalities, and dynamics of measurable residual disease (MRD) are known to influence the outcomes and contribute to disease recurrence. ${ }^{7-11}$ HSCT is recognized as a standard procedure in patients who relapse and subsequently achieve CR2., ${ }^{4,12}$ To evaluate the results of HSCT in CBF AML patients in CR2, we decided to perform a retrospective study using registry data from the Acute Leukemia Working Party (ALWP) of the European Society for Blood and Marrow Transplantation (EBMT). The EBMT is a non-profit, scientific society representing more than 600 transplant centers, mainly in Europe. Member centers are required to report all consecutive stem cell transplantations and follow ups once a year. Data are entered, managed, and maintained in a central database with internet access; each EBMT center is represented in this database. Audits are routinely performed to determine accuracy of data. Before transplantation, patients or legal guardians provide informed consent authorizing the use of their anonymized personal information for research purposes.

\section{Methods}

\section{Patients and data selection}

The study was approved by the ALWP Institutional Review Board and included all adult patients undergoing HSCT in the period from the year 2000 to 2014 reported to the EBMT. The centers were asked by survey to provide data on all patients with $t(8 ; 21)$ or inv(16) to verify the cytogenetic aberrations and to update the transplantation outcomes using designated clinical forms. The patients had to have de novo CBF AML, with classical cytogenetics confirmation of $\mathrm{t}(8 ; 21)$ or inv(16) at initial diagnosis, undergoing HSCT in hematologic CR2, defined as less than $5 \%$ blasts in the bone marrow (BM) and absence of extramedullary involvement, and regardless of current peripheral blood ( $\mathrm{PB}$ ) counts (i.e. bona fide $\mathrm{CR}$ or $\mathrm{CR}$ with incomplete hematologic recovery). All patients received $\mathrm{BM}$ or $\mathrm{PB}$ transplantation (BMT, PBSCT) from matched sibling (MSD) or unrelated donors (UD) after myeloablative (MAC) or reduced intensity (RIC) conditioning, as defined by the
EBMT criteria. ${ }^{13}$ The variables selected to assess outcomes were: age, type of AML, white blood cell count, presence of extramedullary involvement at diagnosis, additional cytogenetic abnormalities, time from diagnosis to CR1, duration of CR1, time from diagnosis and from CR2 to transplantation, molecular remission status at transplantation, Karnofsky performance score (KPS) at transplantation, sex matching of patients and donors, cytomegalovirus (CMV) serological status of patients and donors, year of transplantation, type of the donor, source of stem cells, conditioning intensity, and in vivo T-cell depletion.

\section{End points and statistical analysis}

The primary end point was leukemia-free survival (LFS). Secondary end points were: overall survival (OS), relapse incidence (RI), non-relapse mortality (NRM), graft-versus-host diseasefree and leukemia-free survival (GRFS), as well as acute and chronic graft-versus-host disease (aGvHD and cGvHD). LFS was defined as survival without any symptoms of disease recurrence. OS was defined as probability of survival from transplantation to the last follow up. Relapse was defined as presence of $>5 \%$ blasts in the BM or extramedullary disease after transplantation. NRM was defined as mortality from any cause not related to disease recurrence and GRFS was defined as survival without leukemia, aGvHD grade III-IV or extensive cGvHD. ${ }^{14}$ Minimal residual disease (MRD) was measured in the BM during the interval between last chemotherapy and transplantation. Real-time quantitative polymerase chain reaction (RT-qPCR) was used for RUNX1RUNX1T1 and CBFB-MYH11 quantification. MRD results were reported by the centers as absent (MRDneg) or present (MRDpos) in line with their local guidelines. Acute GvHD was graded according to Glucksberg criteria. ${ }^{15}$ Surviving patients were censored at last follow up. Probabilities of LFS, OS, and GRFS were calculated using Kaplan-Meier estimates. Cumulative incidence functions (CIF) were used to determine RI and NRM in a competing risk setting with each other. Univariate analyses were performed using Gray's test for CIF and the log-rank test for LFS and OS. For all univariate analyses, continuous variables were categorized and the median was used as cut-off point. Associations of patient and transplantation characteristics with outcomes were evaluated in multivariate analysis using Cox proportional hazards model. Multivariate models were built by using stepwise selection procedure. Results were expressed as the hazard ratio (HR) with 95\% Confidence Interval (CI). All tests were two-sided. The type1 error rate was fixed at 0.05 for determination of factors associated with time to event outcomes. Statistical analyses were performed with SPSS 24 (SPSS Inc. /IBM, Armonk, NY, USA) and R 1.3.0 (R Development Core Team, Vienna, Austria) software packages.

\section{Results}

The detailed characteristics of the 631 patients from 181 transplant centers who met the study inclusion criteria are shown in Table 1 . Three hundred and sixty-six patients $(58 \%)$ harbored inv(16) and $265(42 \%) \mathrm{t}(8 ; 21)$. The two groups were compared for essential patient and transplant characteristics (Online Supplementary Table S1). The differences included: sex of the patients [with more males in the $t(8 ; 21)$ group], time from diagnosis to transplantation [which was longer in the $t(8 ; 21)$ group], and time from diagnosis to CR1 [which was also longer in the $t(8 ; 21)$ group]. Altogether there were $361(57 \%)$ males and 270 $(43 \%)$ females. Median age at transplantation was 41.7 years [range 18-73, interquartile range (IOR) 31.3-51.2], 
Table 1. Patients' and transplant characteristics. Percentage values in parentheses refer to reported data.

\begin{tabular}{|c|c|}
\hline Number of patients & 631 \\
\hline Median follow up, months (range) & $59.6(0.9-201)$ \\
\hline Median year of transplantation (range) & $2010(2000-2014)$ \\
\hline $\begin{array}{l}\text { Type of AML } \\
\text { inv(16) } \\
t(8 ; 21)\end{array}$ & $\begin{array}{l}366(58 \%) \\
265(42 \%)\end{array}$ \\
\hline Median age at transplantation, years (range; IQR) & $41.7(18-73 ; 31.3-51.2)$ \\
\hline Median CR1 duration, days (range; IQR) & $318(6-2380 ; 246-474)$ \\
\hline $\begin{array}{l}\text { Median time from diagnosis to transplantation, } \\
\text { months (range; IQR) }\end{array}$ & $17(3.5-222.9 ; 14-22.5)$ \\
\hline $\begin{array}{l}\text { Sex } \\
\text { Male } \\
\text { Female }\end{array}$ & $\begin{array}{l}361(57.2 \%) \\
270(42.8 \%)\end{array}$ \\
\hline $\begin{array}{l}\text { Donors } \\
\text { Matched siblings } \\
\text { Unrelated }\end{array}$ & $\begin{array}{l}264(42 \%) \\
367(58 \%)\end{array}$ \\
\hline $\begin{array}{l}\text { Additional chromosomal abnormalities } \\
\text { No abnormality reported } \\
3 \text { or more abnormalities } \\
\text { Abn5 } \\
\text { Abn7 } \\
\text { Del } 9 \\
\text { Del X or Y } \\
\text { Trisomy } 22 \\
\text { Trisomy } 8 \\
\text { Hyperdiploidy } \\
\text { Hypodiploidy } \\
\text { Undefined/other abnormalities }\end{array}$ & $\begin{array}{c}497(79 \%) \\
32(5 \%) \\
2(0.3 \%) \\
10(1.6 \%) \\
5(0.8 \%) \\
18(2.9 \%) \\
9(1.4 \%) \\
10(1.6 \%) \\
4(0.6 \%) \\
7(1.1 \%) \\
34(5.39)\end{array}$ \\
\hline $\begin{array}{l}\text { Molecular remission at transplantation } \\
\text { Molecular CR } \\
\text { No molecular CR } \\
\text { Missing }\end{array}$ & $\begin{array}{c}343(73.3 \%) \\
125(26.7 \%) \\
163\end{array}$ \\
\hline $\begin{array}{l}\text { Karnofsky performance score } \\
\quad<80 \\
\geq 80 \\
\text { Missing }\end{array}$ & $\begin{array}{l}16(2.8 \%) \\
559(97.2 \%) \\
56\end{array}$ \\
\hline $\begin{array}{l}\text { Conditioning intensity } \\
\text { Myeloablative } \\
\text { Reduced intensity } \\
\text { Missing }\end{array}$ & $\begin{array}{c}424(67.5 \%) \\
204(32.5 \%) \\
3\end{array}$ \\
\hline $\begin{array}{l}\text { Source of stem cells } \\
\text { Bone marrow } \\
\text { Peripheral blood }\end{array}$ & $\begin{array}{l}117(18.5 \%) \\
514(81.5 \%)\end{array}$ \\
\hline $\begin{array}{l}\text { GvHD prophylaxis } \\
\text { CsA based } \\
\text { Tacrolimus based } \\
\text { PTCY } \\
\text { Other } \\
\text { Missing }\end{array}$ & $\begin{array}{c}584(92.6 \%) \\
26(4 \%) \\
6(1 \%) \\
10(1.6 \%) \\
5(0.8 \%)\end{array}$ \\
\hline $\begin{array}{l}\text { In vivo T-cell depletion } \\
\text { Yes } \\
\text { No } \\
\text { Missing }\end{array}$ & $\begin{array}{l}325(51.8 \%) \\
302(48.2 \%) \\
4\end{array}$ \\
\hline $\begin{array}{l}\text { Donor sex } \\
\text { Male } \\
\text { Female } \\
\text { Missing }\end{array}$ & $\begin{array}{c}369(59.4 \%) \\
252(40.6 \%) \\
10\end{array}$ \\
\hline Female to male transplantation & $133(21.2 \%)$ \\
\hline $\begin{array}{l}\text { CMV serology } \\
\text { Patient CMV IgG positive } \\
\text { Donor CMV IgG positive }\end{array}$ & $\begin{array}{c}387(63 \%) \\
305(49.9 \%)\end{array}$ \\
\hline
\end{tabular}

continued in next column

\begin{tabular}{lc} 
Engraftment & \\
Yes & $619(98.7 \%)$ \\
No & $8(1.3 \%)$ \\
Missing & 4 \\
aGvHD grade II-IV & \\
Yes & $171(27.9 \%)$ \\
No & $443(72.1 \%)$ \\
Missing & 17 \\
\hline cGvHD & \\
Yes & $279(46.7 \%)$ \\
No & $318(53.3 \%)$ \\
Missing & 34 \\
\hline
\end{tabular}

AML: acute myeloid leukemia; IQR: interquartile range; CR1: first complete remission abn 5: abnormalities of chromosome 5; abn 7: abnormalities of chromosome 7; del 9 complete or partial deletion of chromosome 9; del X or Y, deletion of chromosome X or Y; trisomy 22: trisomy of chromosome 22 ; trisomy 8: trisomy of chromosome 8; CR complete remission; GvHD: graft-versus-host disease; CsA: cyclosporine A; PTCY: posttransplant cyclophosphamide; CMV IgG: cytomegalovirus-specific immunoglobulin G antibody; aGvHD: acute graft-versus-host disease; cGvHD: chronic graft-versus-host disease.

and the median year of transplantation was 2010. Nearly half of the procedures were performed between the years 2010 and 2014. Additional analysis of transplantation intervals 2000-2005, 2006-2009, and 2010-2014 periods did not reveal any significant differences in outcomes. Twenty-one percent of patients had additional cytogenetic aberrations detected at diagnosis. The most frequent of them was presence of three or more abnormalities $(32.5 \%)$. There was a low frequency of reports of accompanying molecular abnormalities (cKIT mutations, FLT3ITD, NRAS mutations and KRAS mutations) which precluded subset evaluation. The most frequent available information on co-mutation pattern was FLT3-ITD, which was reported in 26 patients, with a similar distribution between the inv(16) and the $t(8 ; 21)$ groups (14 and 12 patients, respectively). Three hundred and forty-three (73.3\%) patients were MRDneg, while $125(26.7 \%)$ were MRDpos before transplantation. There was a trend for higher frequency of MRDpos patients in the $t(8 ; 21)$ compared to the inv(16) subgroup $(P=0.06)$ (Online Supplementary Table S1). Further analysis showed significant differences in terms of LFS, OS, and relapse in favor of inv(16) compared to $t(8 ; 21)$ AML in MRDneg but not MRDpos patients (Online Supplementary Table S2). Engraftment was achieved in $619(98.7 \%)$ patients.

\section{Leukemia-free survival}

The 2- and 5-year probability of LFS was $59.1 \%$ (95\%CI: $55.2-63.1$ ) and $54.1 \%$ (95\%CI: 50-58.2), respectively. In univariate analysis, LFS was significantly higher for patients with inv $(16)$ compared to patients with $t(8 ; 21)$ (63.8\% vs. $52.5 \%, P=0.003$ ) (Figure $1 \mathrm{~A}$ ). Presence of three or more additional cytogenetic abnormalities at diagnosis resulted in worse LFS $(37.5 \%$ vs. $60.4 \%, P=0.002)$. For MRDpos patients, the probability of LFS was $49 \%$ compared to $61.6 \%$ for patients who were MRDneg $(P=0.046)$ (Figure 2A). Performance status was also an important factor, with 2-year LFS probability of $59.9 \%$ for patients with KPS $\geq 80$ versus $37.5 \%$ for those with KPS $<80(P=0.003)$. The results of the univariate analysis are provided in Online Supplementary Table S3. In multivariate analysis, the type of CBF AML [ $t(8 ; 21)$ versus inv(16)] was an independent factor for LFS (HR $=1.40,95 \% \mathrm{CI}$ : 1.05-1.86, $P=0.022)$ as was presence of three or more additional cyto- 
Table 2. Multivariate analysis using Cox proportional hazards model. Variables with $P<0.15$ in univariate analysis were included in the model.

\begin{tabular}{|c|c|c|c|c|}
\hline & & $P$ & HR & $95 \%$ CI \\
\hline LFS & $\begin{array}{l}\mathrm{t}(8 ; 21) \text { vs. inv }(16) \\
\geq 3 \text { chromosomal abnormalities vs. no } \\
\text { Molecular MRDneg vs. MRDpos } \\
\text { KPS } \geq 80 \text { vs. }<80\end{array}$ & $\begin{array}{l}0.022 \\
0.004 \\
0.080 \\
0.006\end{array}$ & $\begin{array}{l}1.40 \\
2.09 \\
0.76 \\
0.32\end{array}$ & $\begin{array}{l}1.05-1.86 \\
1.27-3.42 \\
0.55-1.03 \\
0.14-0.73\end{array}$ \\
\hline OS & $\begin{array}{l}\mathrm{t}(8 ; 21) \text { vs. } \operatorname{inv}(16) \\
\geq 3 \text { chromosomal abnormalities vs. no } \\
\text { KPS } \geq 80 \text { vs. }<80\end{array}$ & $\begin{array}{c}0.00002 \\
0.037 \\
0.002\end{array}$ & $\begin{array}{l}1.76 \\
1.68 \\
0.36\end{array}$ & $\begin{array}{l}1.35-2.28 \\
1.03-2.72 \\
0.19-0.68\end{array}$ \\
\hline RI & $\begin{array}{l}\mathrm{t}(8 ; 21) \text { vs. inv }(16) \\
\geq 3 \text { chromosomal abnormalities vs. no } \\
\text { Time from diagnosis to transplantation (>median }>) \\
\text { RIC vs. MAC } \\
\text { Molecular MRDneg vs. MRDpos }\end{array}$ & $\begin{array}{l}0.002 \\
0.011 \\
0.023 \\
0.017 \\
0.043\end{array}$ & $\begin{array}{l}1.89 \\
2.31 \\
0.97 \\
1.64 \\
0.65\end{array}$ & $\begin{array}{l}1.26-2.84 \\
1.23-4.40 \\
0.94-0.99 \\
1.09-2.47 \\
0.42-0.99\end{array}$ \\
\hline NRM & KPS $\geq 80$ vs. $<80$ & 0.001 & 0.29 & $0.14-0.59$ \\
\hline GRFS & $\begin{array}{l}\text { Molecular MRDneg vs. MRDpos } \\
\geq 3 \text { chromosomal abnormalities vs. no } \\
\text { In vivo TCD } v \text { s. no } \\
\text { Donor CMV IgG negative vs. positive }\end{array}$ & $\begin{array}{l}0.054 \\
0.031 \\
0.027 \\
0.058\end{array}$ & $\begin{array}{l}0.77 \\
1.61 \\
0.76 \\
0.79\end{array}$ & $\begin{array}{l}0.60-1.00 \\
1.04-2.47 \\
0.60-0.97 \\
0.99-1.61\end{array}$ \\
\hline aGvHD II-IV & RIC vs. MAC & 0.011 & 0.64 & $0.45-0.90$ \\
\hline cGvHD & $\begin{array}{l}\text { In vivo TCD } v s . \text { no } \\
\text { Donor CMV IgG positive } v s . \text { negative } \\
\text { PBSCT vs. BMT }\end{array}$ & $\begin{array}{l}<10-5 \\
0.004 \\
0.003\end{array}$ & $\begin{array}{l}0.56 \\
1.45 \\
1.72\end{array}$ & $\begin{array}{l}0.43-0.72 \\
1.13-1.87 \\
1.20-2.46\end{array}$ \\
\hline
\end{tabular}

LFS: leukemia-free survival; MRDneg: minimal residual disease negative; MRDpos: minimal residual disease positive; KPS: Karnofsky performance score; OS: overall survival; RI relapse incidence; RIC: reduced intensity conditioning; MAC: myeloablative conditioning; NRM: non-relapse mortality; GRFS: graft-versus-host disease-free, relapse-free survival; CMV IgG: cytomegalovirus-specific immunoglobulin G antibody; TCD: T-cell depletion; aGvHD II-IV: acute graft-versus-host disease, grades II to IV;cGVHD: chronic graft-versushost disease; PBSCT: peripheral blood stem cell transplantation; BMT: bone marrow transplantation.

genetic abnormalities (HR=2.09, 95\% CI: $1.27-3.42$,

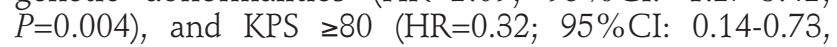
$P=0.32$ ). In multivariate analysis, MRDneg was not an independent prognostic factor for LFS (HR=0.76; 95\% CI: $0.55-1.03, P=0.08$ ) (Table 2).

\section{Overall survival}

Two- and 5-year OS probability for the whole group was $65 \%$ (95\% CI: 61.2-68.9) and 58.2\% (95\%CI: $54.1-$ $62.3)$, respectively. In univariate analysis, patients with $\mathrm{t}(8 ; 21)$ AML had a lower probability of OS compared to those with $\operatorname{inv}(16)(57 \%$ vs. $70.5 \%, P=0.0003)$ (Figure 1B). Three or more additional cytogenetic abnormalities was associated with lower OS (49.6\% vs. $65.9 \%, P=0.013)$. Performance status at transplantation influenced OS. OS of patients with $\mathrm{KPS} \geq 80$ was $66.1 \%$ versus $37.5 \%$ in those with $\mathrm{KPS}<80$ ( $P=0.003)$ (Online Supplementary Table S3). MRDneg was not significantly associated with OS (Figure 2B). Multivariate analysis confirmed the findings of the univariate analysis. AML with $t(8 ; 21)$, additional cytogenetic abnormalities, and KPS $<80$ were the three independent prognostic factors for significantly worse OS with HR 1.76 (95\%CI: 1.35-2.28, $P=0.00002)$, HR 1.68 (95\% CI: $1.03-2.72, P=0.037$ ), and HR 0.36 for $\mathrm{KPS} \geq 80$ (95\%CI: $0.19-0.68, P=0.002)$, respectively (Table 2). In multivariate analysis, MRD status was not an independent prognostic factor for OS $(59.9 \%$; 95\% CI: 50.8-68.9 vs. 65.8\%; 95\% CI: 60.7-71, P=0.47). Age at HSCT (below or above the median) did not affect OS (66.5\%; 95\% CI: 61.171 vs. 63.6\%; 95\% CI: 58.1-69, $P=0.39)$.

\section{Relapse incidence}

The risk of relapse at two and at five years was estimated at $19.8 \%$ (95\% CI: 16.7-23.1) and $22.5 \%$ (95\% CI: $19.2-$ 26). In patients with $t(8 ; 21)$, the risk of relapse at two years was significantly higher: $25.8 \%$ versus $15.6 \%$ in those with inv (16) $(P=0.009)$ (Figure 1C). The risk of relapse was higher in patients with three or more additional chromosomal aberrations ( $34.4 \%$ vs. $19 \%, P=0.03$ ). In the whole cohort, MRDneg patients had a significantly decreased risk of relapse compared to MRDpos patients (16.2\% vs. 29.3\%, $P=0.003$ ) (Figure 2C). In patients with CR1 shorter than the median (318 days), the risk of relapse after transplantation was higher $(26.4 \%$ vs. $13 \%, P<$ 0.001). Time from diagnosis to transplantation was also significant. In patients receiving HSCT within a shorter time than the median (17 months from diagnosis), the risk of relapse was higher $(26.4 \%$ vs. $13.1 \%, P<0.001)$. Conditioning intensity was also important. Patients receiving RIC experienced more leukemia relapses compared to those receiving MAC $(25.9 \%$ vs. $17 \%, P=0.002)$. Finally, in vivo $\mathrm{T}$-cell depletion led to more recurrences $(22.6 \%$ vs. $16.7 \%$ in patients transplanted without T-cell depletion $(P=0.02)$ (Online Supplementary Table S3). In multivariate analysis, $t(8 ; 21)$ versus inv(16), presence of three or more additional chromosomal abnormalities, time from diagnosis to transplantation ( $>v s . \leq$ median), MRDneg, and RIC were independent significant prognostic factors for relapse. The corresponding HR values for those factors were 1.89 (95\%CI; 1.26-2.84, $P=0.002), 2.31$ (95\% CI: 1.23-4.4, $P=0.011$ ), 0.97 (95\% CI: 0.94-0.99, $P=0.023), 0.65$ (95\% CI: 0.42-0.99, $P=0.043)$, and 1.64 (95\% CI: 1.09-2.47, $P=0.017)$, respectively. In vivo T-cell depletion was not confirmed to be an independent risk factor for relapse in multivariate analysis (Table 2).

\section{Non-relapse mortality}

The 2- and 5-year incidence of NRM was 20.9\% (95\% CI: $17.7-24.2)$ and $23.3 \%$ (95\% CI: 19.9-26.8), respectively. In univariate analysis, KPS $<80$ versus $\geq 80$ was 

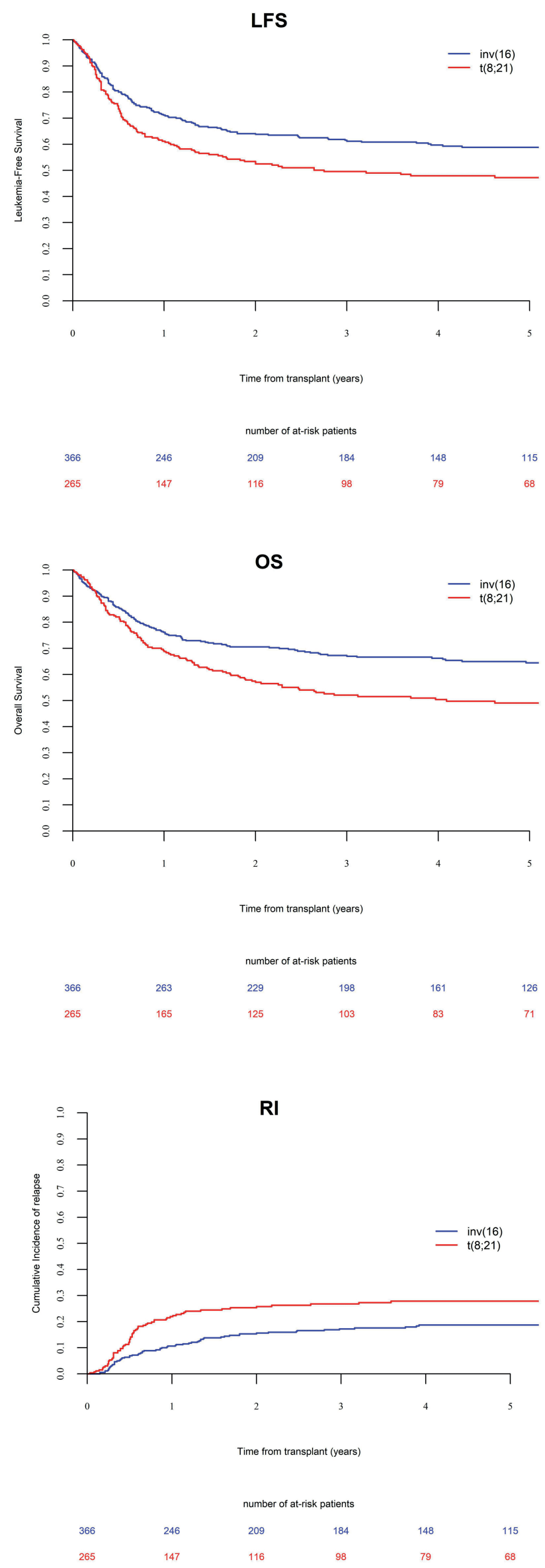

Figure 1. Leukemia-free survival (LFS), overall survival (OS), and relapse incidence (RI) in patients with core-binding factor acute myeloid leukemia (CBF AML) transplanted in second complete remission for patients with inv(16) versus $\mathrm{t}(8 ; 21)$. 2-year probability of LFS: $63.8 \%$ (95\% Cl: $58.8-68.8)$ vs. $52.5 \%$ (95\% Cl: 46.2-58.8), $P=0.003$. 2-year probability of OS: $70.5 \%$ (95\% Cl: 65.8 $75.3)$ vs. $57 \%$ (95\% Cl: 50.7-63.2), $P=0.0003$. 2 -year risk of relapse: $15.6 \%$ (95\% Cl: 12-19.6) vs. $25.8 \%$ (95\% Cl: 20.5-31.4), $P=0.009$.

strongly associated with NRM (50\% vs. $19.8 \%, P=0.002)$ Patients in whom CR1 duration was shorter than the median, or those who were transplanted at a shorter time from diagnosis than the median, experienced decreased NRM $(17.1 \%$ vs. $25.8 \%, P=0.007$ and $18 \%$ vs. $24 \%$, $P=0.01$, respectively) (Online Supplementary Table S3). In multivariate analysis, only performance status was an independent risk factor for NRM; HR 0.29 (95\% CI: 0.14 $0.59, P=0.001)$ for patients with $\mathrm{KPS} \geq 80$ versus those with KPS $<80$ (Table 2).

\section{Graft-versus-host disease-free and leukemia-free survival}

The 2- and 5-year probability of GRFS was $40.2 \%$ (95\%CI: 36.2-44.2) and 34.6\% (95\% CI: 30.6-38.6), respectively. The 2 -year probability of GRFS for patients with inv (16) was higher than for those with $t(8 ; 21)$ (44.1\% vs. $34.7 \%, P=0.049)$. Presence of three or more additional chromosomal aberrations was significantly associated with worse GRFS (20\% vs. $41.3 \%, P=0.01$ ). Patients who were MRDneg before transplantation had a higher probability of GRFS (42.9\% vs. $29.2 \%, P=0.02)$. Similarly, those who received in vivo T-cell depletion had a higher GRFS (46.1\% vs. 33.9\%, $P=0.004)$. Finally, there was a trend for better GRFS in patients transplanted from CMV seronegative versus seropositive donors (41.8\% vs. $38.4 \%, P=0.07$ ) (Online Supplementary Table S3). In multivariate analysis, factors independently associated with GRFS were three or more cytogenetic abnormalities and in vivo T-cell depletion (HR 1.61; 95\% CI: 1.04-2.47, $P=0.03$ and HR 0.76; 95\%CI: 0.6-0.97, $P=0.027$, respectively). Transplantation from CMV negative donors and MRDneg status were associated with a trend for better GRFS (HR0.79; 95\%CI: 0.62-1, $P=0.058$ and HR 0.77; 95\%CI: $0.6-1.0, P=0.054$, respectively) (Table 2 ).

\section{Graft-versus-host disease}

The incidence of aGvHD grades II to IV and III-IV was 28\% (95\%CI: 24.5-31.6) and 9.5\% (95\%CI: 7.3-12), respectively. In univariate analysis, transplantation from MSD compared to UD was associated with lower incidence of grade II-IV aGvHD (24.1\% vs. $30.8 \%, P=0.049)$. Grade II-IV aGvHD was higher in patients transplanted with BM vs. PB grafts (36\% vs. 26.1\%, P=0.04). MAC in comparison to RIC was associated with increased incidence of aGvHD grade II-IV (30.8\% vs. $21.6 \%, P=0.01)$. In vivo $\mathrm{T}$-cell depletion reduced grade II-IV (23.6\% vs. $32.7 \%, P=0.01)$ and grade III-IV $(5.7 \%$ vs. $13.6 \%$, $P=0.009$ ) aGVHD incidence (Online Supplementary Table S3). In multivariate analysis, only intensity of conditioning regimen (RIC vs. MAC) was an independent prognostic factor for aGvHD grade II-IV: HR 0.64 (95\% CI: 0.45 0.9), $P=0.011$ (Table 2).

The incidence of $\mathrm{cGvHD}$ at two and five years post transplant was $46.7 \%$ (95\%CI: 42.5-50.8) and $48.4 \%$ (95\%CI: 44-52.4), respectively. Transplantation from 

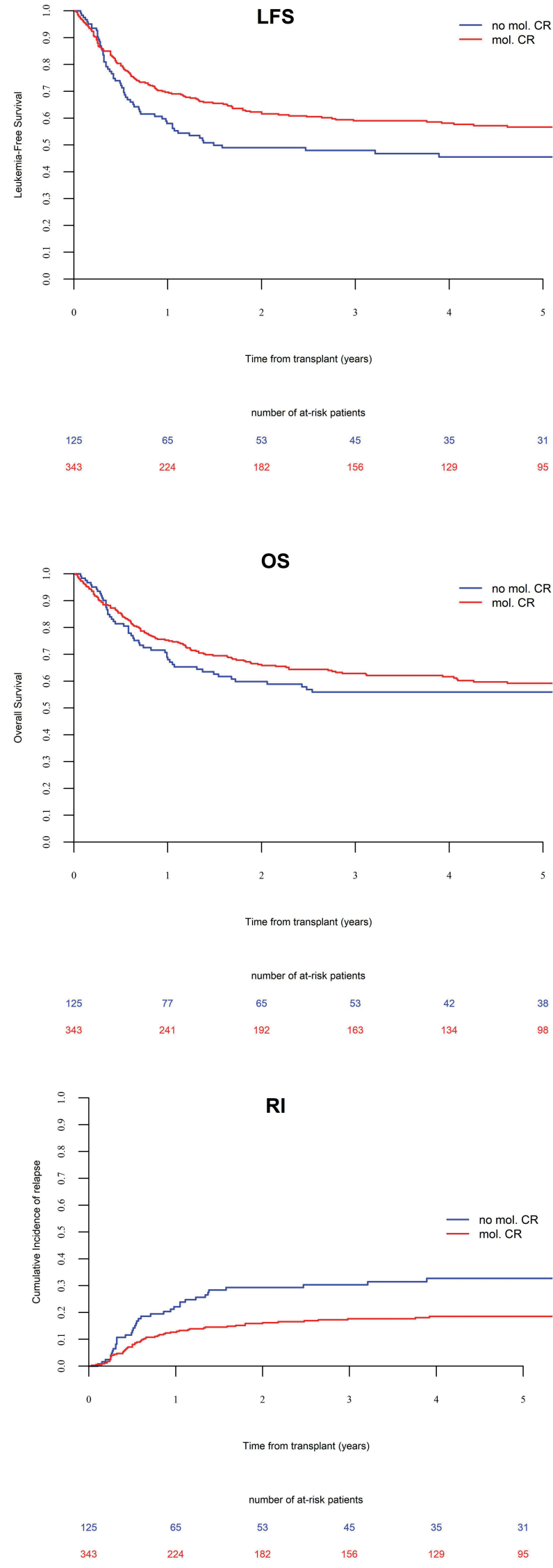

Figure 2. Leukemia-free survival (LFS), overall survival (OS), and relapse incidence (RI) in patients with core-binding factor acute myeloid leukemia in patients without versus with molecular remission pre-transplant. 2-year probability of LFS: $49 \%$ (95\% Cl: 39.8-58.2) vs. $61.6 \%$ (95\%Cl: 56.3-66.9), $P=0.046$ 2-year probability of OS: $59.9 \%$ (95\%Cl: 50.8-68.9) vs. $65.8 \%$ (95\%Cl: $60.7-71)$, $P=0.47$. 2-year risk of relapse: $29.3 \%(95 \% \mathrm{Cl}$ : $21.2-37.8)$ vs. $16.2 \%(95 \% \mathrm{Cl}$ : 12.4-20.4), $P=0.003$.

Table 3. Mortality during follow up.

\begin{tabular}{lc} 
Causes of death & Number \\
Total & 257 \\
Original disease & 83 \\
\hline Infection & 62 \\
Graft-versus-host disease & 59 \\
\hline Other related to transplantation & 21 \\
Interstitial pneumonitis & 9 \\
\hline Sinusoidal obstruction syndrome & 5 \\
Hemorrhage & 4 \\
\hline Second malignancy & 4 \\
Cardiac toxicity & 2 \\
\hline Missing & 8 \\
\hline
\end{tabular}

female versus male donors was associated with increased risk of $\mathrm{cGvHD}(52.1 \%$ vs. $43.4 \%, P=0.01)$; the same was true for female to male transplantations versus other combinations $(55.2 \%$ vs. $44.5 \%, P=0.03)$. Transplantation from CMV positive versus CMV negative donors also correlated with increased risk of cGvHD (53.2\% vs. $40.5 \%$, $P=0.002)$. BM versus $\mathrm{PB}$ grafts resulted in lower incidence of cGVHD (37.1\% vs. $49.1 \%, P=0.04)$. In vivo T-cell depletion decreased risk of cGVHD ( $37.7 \%$ vs. $55.9 \%, P<0.001)$ (Online Supplementary Table S3). In multivariate analysis, in vivo T-cell depletion was an independent factor for decreased risk of $\mathrm{cGvHD}(\mathrm{HR}=0.56$; $95 \% \mathrm{CI}$ : 0.43-0.72, $P<0.001$ ), while PBSCT and CMV donor seropositivity were associated with increased risk of cGVHD ( $\mathrm{HR}=1.72$; $95 \% \mathrm{CI} ; 1.2-2.46, P=0.003$ and $\mathrm{HR}=1.45$; $95 \% \mathrm{CI}$ : $1.13-$ $1.87, P=0.004$, respectively) (Table 2 ).

\section{Mortality}

During follow up, 257 of 631 patients died. The main causes of death were recurrence of the original disease, infection, and GvHD (Table 3).

\section{Discussion}

This retrospective analysis of HSCT in CBF AML in second hematologic CR was based on a large number of patients reported to the EBMT. Chemotherapy alone after relapse in patients with favorable risk AML is able to produce 5-year survival in $42-44 \%$ of patients. ${ }^{10,17}$ Allogeneic HSCT is recommended by leading organizations in Europe and the USA as consolidation treatment for AML patients achieving CR $2 .{ }^{18}$ In our study, the results of transplantation in terms of OS and LFS were a little worse than those described previously for patients with CBF AML transplanted in CR1 and comparable with published outcomes of HSCT performed in CR2. ${ }^{19,20}$ Similarly to those 
studies, in our group, patients with inv(16) had a higher probability of LFS, OS, and a lower risk of relapse than those with $t(8 ; 21)$. Interestingly, these end points reported in most papers for patients treated with chemotherapy alone are not usually different for inv(16) and t(8;21) AML. On the other hand, the MD Anderson study, for example, pointed out that patients diagnosed with $t(8 ; 21)$ have a worse prognosis than those with inv(16).

Response to chemotherapy with clearance of RUNX1RUNX1T1 and CBFB-MYH11 evaluated with RT-qPCR, as well as additional molecular aberrations detected at diagnosis, but not type of CBF AML per se, are most frequently emphasized as the factors determining outcome in chemotherapy-treated patients., ${ }^{912,22}$ Presence of MRD assessed with flow cytometry in AML before transplantation is a recognized risk factor for inferior outcome. ${ }^{23}$ Molecular evaluation of MRD in CBF AML before transplantation has not been extensively studied to date. In our cohort, MRDneg patients had a significantly decreased risk of relapse compared with MRDpos patients $(\mathrm{HR}=0.65, P=0.043)$; this translated into a trend for improved LFS ( $\mathrm{HR}=0.76, P=0.08$ ) and GRFS ( $\mathrm{HR}=0.77$, $P=0.054)$ but showed no significant influence on $O S$ $(P=0.47)$. Data analysis revealed that MRDpos patients more frequently received donor lymphocyte infusions or subsequent transplants after relapse than MRDneg patients. Those therapeutic interventions, and probably lack of statistical power, may explain why we did not find a significant difference in $O S$ in favor of MRDneg patients. The results of our study indicate that even patients who are $\mathrm{MDR}$ pos can expect survival advantage from transplantation compared to those who are treated with chemotherapy alone. ${ }^{9}$ A recent paper showed that evaluation of RUNX1-RUNX1T1 was useful to predict relapse not only before but also after HSCT. ${ }^{24}$ It should be emphasized that the kinetics of relapse in $\operatorname{inv}(16)$ and $t(8 ; 21)$ patients differ, and the latter group requires more frequent molecular testing. ${ }^{25}$

According to the 2017 European Leukemia Net and National Comprehensive Cancer Network guidelines, additional cytogenetic aberrations in CBF AML do not modify disease risk. ${ }^{4,26}$ In our study group, the presence of concurrent three or more chromosomal abnormalities had a marked deleterious effect on relapse $(\mathrm{HR}=2.31$, $P=0.011)$, LFS ( $\mathrm{HR}=2.09, P=0.004)$, and even $\mathrm{OS}(\mathrm{HR}=1.68$, $P=0.037)$ after HSCT. Indeed, earlier reports documented worse outcomes in newly diagnosed CBF AML patients with three or more cytogenetic abnormalities. ${ }^{5}$ This finding may indicate a more complex clonal evolution, and could support the adoption of anticipated measures to avoid relapse, such as indication of transplantation in first remission.

Not surprisingly, in our study, performance status was a strong independent risk factor for NRM, LFS, and OS. Thus, patients with KPS $\geq 80$ had decreased NRM and improved LFS and OS, which was similar to the findings of previous studies. ${ }^{27}$

The intensity of conditioning regimen in the current analysis favored MAC over RIC in terms of relapse. Comparable findings were described in a recent EBMT ALWP study in patients transplanted for secondary AML with additional benefit of higher probability of LFS and $\mathrm{OS}$ in individuals receiving MAC. ${ }^{28}$ The results of an
American phase III prospective randomized trial of MAC versus RIC in AML and myelodysplastic syndrome patients published in 2017 also revealed statistically higher relapse rates and worse LFS with a trend for decreased OS after RIC. ${ }^{29}$ In contrast, in a German randomized study including AML patients published a few years earlier, RIC and MAC yielded identical results for both types of conditioning, even in terms of disease recurrence. ${ }^{30}$ In our cohort, conditioning intensity had no significant impact on LFS or OS. In the German trial, MAC was also a predictor for aGvHD. Similarly, in our study, MAC was the only independent risk factor for clinically significant, grade II-IV aGvHD. The same correlation had been described previously, and is supported by the concept of a more pronounced inflammatory reaction after MAC. ${ }^{31}$

Independent factors influencing cGvHD in our study were: in vivo TCD, the use of $\mathrm{PBSC}$ versus $\mathrm{BM}$, and transplantation from CMV seropositive donors; these findings are in agreement with previous literature. ${ }^{32,33}$ Only recently, possible mechanisms linking CMV immunity and cGvHD were studied in HSCT recipients. In patients with cGvHD, a higher proportion of donor-origin high-affinity CMV-specific cytotoxic T lymphocytes was demonstrated. ${ }^{34}$ The composite end point described as GRFS represents the most desirable outcome of HSCT. In our study, 2- and 5-year probabilities of GRFS were $40.2 \%$ and $34.6 \%$, respectively. Recently, a large analysis of 5,059 AML patients from the EBMT database defined transplantation from unrelated donors, PB stem cell transplants, and unfavorable cytogenetics as prognostic factors for worse GRFS. In contrast, in vivo TCD was associated with better results and was the main beneficial factor for GRFS. ${ }^{35}$ In our cohort, type of donor and source of stem cells did not have a significant impact on GRFS, which may be due to a considerably smaller study sample. Adverse cytogenetics decreased, while in vivo TCD increased the probability of GRFS in our patients, which is in line with the results of the above-mentioned study.

Our registry-based, retrospective study has various well-known limitations. For example, due to low reporting, we were not able to investigate the prognostic impact of additional genetic co-mutations frequently observed in CBF-AML, such as mutations in signaling pathways KIT, NRAS, KRAS and FLT3. ${ }^{36}$

The most important findings of our study show that HSCT in CBF AML in CR2 was able to cure a large proportion of patients, with 2-year and 5-year OS 65\% and $58.2 \%$, respectively. The survival of patients with inv(16) was better than those with $t(8 ; 21)$; an observation which confirms a substantial underlying difference between the two CBF AML subtypes also in the transplant setting. Based on our results, CBF AML patients should receive MAC rather than RIC, if eligible. Although patients who were MRDneg had lower risk of relapse and higher probability of survival without recurrence of leukemia, a significant proportion of MRDpos patients obtained durable response following HSCT. In view of our study, lack of MRD clearance should not be considered a contraindication for allogeneic transplantation.

\section{Acknowledgments}

The authors would like to thank all colleagues from 181 reporting centers for providing data for the analysis. 


\section{References}

1. Grimwade D, Walker H, Oliver F, et al. The importance of diagnostic cytogenetics on outcome in AML: analysis of 1,612 patients entered into the MRC AML 10 Trial. Blood. 1998;92(7):2322-2333.

2. Solh M, Yohe S, Weidorf D, Ustun C. Corebinding factor acute myeloid leukemia: heterogeneity, monitoring and therapy. Am J Hematol. 2014;89(12):1121-1131.

3. Papaemmanuil E, Gerstung M, Bullinger L, et al. Genomic classification and prognosis in acute myeloid leukemia. $N$ Engl J Med. 2016;374(23):2209-2221.

4. Döhner H, Estey E, Grimwade D, et al. Diagnosis and management of AML in adults: 2017 ELN recommendations from an international expert panel. Blood. 2017;129(4): 424-447.

5. Appelbaum FR, Kopecky KJ, Tallman MS, et al. The clinical spectrum of adult acute myeloid leukaemia associated with core binding factor translocations. Br J Haeamtol. 2006;135(2):165-173

6. Schlenk RF, Benner A, Krauter J, et al. Individual patient data-based meta-analysis of patients aged 16 to 60 years with core binding factor acute myeloid leukemia: a survey of the German Acute Myeloid Leukemia Intergroup. J Clin Oncol. 2004;22(18):3741-3750

7. Marcucci G, Mrózek K, Ruppert AS, et al. Prognostic factors and outcome of core binding factor acute myeloid leukemia patients with $t(8 ; 21)$ differ from those of patients with inv(16): a Cancer and Leukemia Group B study. J Clin Oncol. 2005;23(24):5705-5717.

8. Mosna F, Papayannidis C, Martinelli G, et al. Complex karyotype, older age, and reduced first-line dose intensity determine poor survival in core binding factor acute myeloid leukemia patients with long-term follow-up. Am J Hematol. 2015;90(6):515-523.

9. Jourdan E, Boissel N, Chevret S, et al. Prospective evaluation of gene mutations and minimal residual disease in patients with core binding factor acute myeloid leukemia. Blood. 2013;121(12):2213-2223.

10. LiuYin JA, O'Brien MA, Hills RK, Daly SB, Wheatley K, Burnett AK. Minimal residual disease monitoring by quantitative RT-PCR in core binding factor AML allows risk stratification and predicts relapse: results of the United Kingdom MRC AML-15 trial. Blood. 2012;120(14):2826-2835.

11. Cairoli R, Beghini A, Turrini M, et al. Old and new prognostic factors in acute myeloid leukemia with deranged core-binding factor beta. Am J Hematol. 2013;88(7):594-600.

12. Sureda A, Bader P, Cesaro S, et al. Indications for allo- and auto-SCT for haematological diseases, solid tumors and immune disorders: current practice in Europe, 2015. Bone Marrow Transplant. 2015;50(8):1037-1056.

13. Bacigalupo A, Ballen K, Rizzo D, et al.
Defining the intensity of conditioning regimens: working definitions. Biol Blood Marrow Transplant. 2009;15(12):1628-1633

14. Ruggeri A, Labopin M, Ciceri F, Mohty M, Nagler A. Definition of GvHD-free, relapsefree survival for registry-based studies: an ALWP-EBMT analysis on patients with AML in remission. Bone Marrow Transplant. 2016;51(4):610-611.

15. Glucksberg H, Storb R, Fefer A, et al. Clinical manifestations of graft-versus-host disease in human recipients of marrow from HLAmatched sibling donors. Transplantation. 1974:18(4):295-304

16. Hospital MA, Prebet T, Bertoli S, et al. Corebinding factor acute myeloid leukemia in first relapse: a retrospective study from the French AML intergroup. Blood. 2014;124(8):1312-1319.

17. Burnett AK, Goldstone A, Hills RK, et al Curability of patients with acute myeloid leukemia who did not undergo transplantation in first remission. I Clin Oncol. 2013;31(10):1293-1301

18. Hübel $\mathrm{K}$, Weingart $\mathrm{O}$, Naumann $\mathrm{F}$, et al Allogeneic stem cell transplant in adult patients with acute myelogenous leukemia: a systematic analysis of international guideines and recommendations. Leuk Lymph. 2011;52(3):444-457

19. Joon JH, Kim JW, Jeon YW, et al. Identification of molecular and cytogenetic risk factors for unfavorable core-binding factor-positive adult AML with post-remission treatment outcome analysis including transplantation. Bone Marrow Transpl. 2014;49 (12):1466-1474

20. Kuwatsuka W, Miyamura K, Suzuki R, et al. Hematopoietic stem cell transplantation for core binding factor acute myeloid leukemia: $t(8 ; 21)$ and inv(16) represent different clinical outcomes. Blood. 2009;113(9):2096-2103.

21. Hoyos M, Nomdedeu JF, Esteve J, et al. Core binding factor acute myeloid leukemia: the impact of age, leukocyte count, molecula findings, and minimal residual disease. Eur J Haematol. 2013;91(3):209-218.

22. Duployez N, Marceau-Renaut A, Boissel N et al. Comprehensive mutational profiling of core binding factor acute myeloid leukemia. Blood. 2016;127(20):2451-2459.

23. Walter RB, Buckley SA, Pagel JM, et al. Significance of minimal residual disease before myeloablative allogeneic hematopoietic cell transplantation for AML in first and second complete remission Blood. 2013;122(10):1813-1821.

24. Oin YZ, Wang Y, Xu LP, et al. The dynamics of RUNX1-RUNX1T1 transcript levels after allogeneic hematopoietic stem cell transplantation predict relapse in patients with (8;21) acute myeloid leukemia. J Hematol Oncol. 2017;10(1):44

25. Ommen HB, Schnittger S, Jovanovic JV, et al Strikingly different molecular relapse kinetics in NPM1c, PML-RARA, RUNX1RUNX1T1, and CBFB-MYH11 acute myeloid leukemias. Blood. 2010;115(2):198 205.
26. O'Donnell MR, Tallman MS, Abboud CN, et al. NCCN Guidelines version 2.2018 . Acute myeloid leukemia. Cited 2018, 15 Sept. Available from https://www.nccn.org/ professionals/physician_gls/pdf/aml.pdf

27. Sorror M, Storer B, Sandmaier BM, et al. Hematopoietic cell transplantation-comorbidity index and Karnofsky performance status are independent predictors of morbidity and mortality after allogeneic nonmyeloablative hematopoietic cell transplantation. Cancer. 2008;112(9):1992-2001.

28. Sengsayadeth S, Gatwood KS, Boumendi $\mathrm{A}$, et al. Conditioning intensity in secondary AML with prior myelodysplastic syndrome/myeloproliferative disorders: an EBMT ALWP study. Blood Adv. 2018;2(16):2127-2135

29. Scott BL, Pasquini MC, Logan BR, et al Myeloablative versus reduced-intensity hematopoietic cell transplantation for acute myeloid leukemia and myelodysplastic syndromes. J Clin Oncol. 2017;35(11):11541161

30. Bornhäuser M, Kienast J, Trenschel R, et al Reduced-intensity conditioning versus standard conditioning before allogeneic haemopoietic cell transplantation in patients with acute myeloid leukaemia in first complete remission: a prospective, open-label randomised phase 3 trial. Lancet Oncol. 2012;13(10):1035-1044

31. Couriel DR, Saliba RM, Giralt S, et al. Acute and chronic graft-versus-host disease after ablative and nonmyeloablative conditioning for allogeneic hematopoietic transplantation. Biol Blood Marrow Transplant. 2004:10(3):178-185

32. Jacobsen N, Badsberg JH, Lönnqvist B, et al. Graft-versus-leukaemia activity associated with CMV-seropositive donor, post-transplant CMV infection, young donor age and chronic graft-versus-host disease in bone marrow allograft recipients. The Nordic Bone Marrow Transplantation Group. Bone Marrow Transplant. 1990;5(6):413-418.

33. Ljungman P, Brand R, Hoek J, et al. Donor cytomegalovirus status influences the outcome of allogeneic stem cell transplant: a study by the European group for blood and marrow transplantation. Clin Infect Dis. 2014:59(4):473-481

34. Poiret T, Axelsson-Robertson R, Remberger $\mathrm{M}$, et al. Cytomegalovirus-specific CD8+ Tcells with different T-cell receptor affinities segregate $\mathrm{T}$-cell phenotypes and correlate with chronic graft-versus-host disease in patients post-hematopoietic stem cell transplantation. Front Immunol. 2018:9:760.

35. Battipaglia G, Ruggeri A, Labopin M, et al. Refined graft-versus-host disease/relapsefree survival in transplant from HLA-identical related or unrelated donors in acute myeloid leukemia. Bone Marrow Transplant. 2018;53(10):1295-1303

36. Faber ZJ, Chen X, Gedman AL, et al. The genomic landscape of core-binding facto acute myeloid leukemias. Nat Genet. 2016;48(12):1551-1556. 